\title{
Smoking and relative body weight: an international perspective from the WHO MONICA Project
}

WHO MONICA Project* prepared by A Molarius, J C Seidell, K Kuulasmaa, A J Dobson, S Sans

\begin{abstract}
Study objective-To investigate the magnitude and consistency of the associations between smoking and body mass index (BMI) in different populations.

Design-A cross sectional study.

Setting and participants-About 69000 men and women aged 35-64 years from 42 populations participating in the first WHO MONICA survey in the early and mid 1980s.

Main results-Compared to never smokers, regular smokers had significantly $(\mathbf{p}<0.05)$ lower median BMI in 20 (men) and 30 (women) out of 42 populations (range -2.9 to $0.5 \mathrm{~kg} / \mathrm{m}^{2}$ ). There was no population in which smokers had a significantly higher BMI than never smokers. Among men, the association between leanness and smoking was less apparent in populations with relatively low proportions of regular smokers and high proportions of ex-smokers. Ex-smokers had significantly higher BMI than never smokers in 10 of the male populations but in women no consistent pattern was observed. Adjustment for socioeconomic status did not affect these results.

Conclusions-Although in most populations the association between smoking and BMI is similar, the magnitude of this association may be affected by the proportions of smokers and ex-smokers in these populations.
\end{abstract}

( $(\mathcal{F}$ Epidemiol Community Health 1997;51:252-260)

Numerous epidemiological studies have shown a consistent inverse relationship between smoking and body weight - smokers weigh relatively less than non-smokers, ${ }^{1-11}$ and stopping smoking often leads to weight gain. ${ }^{1-35710^{12-14}}$ It has been shown that this is mainly because smoking increases energy expenditure. ${ }^{15}$ Moreover, the inverse relationship between smoking and relative body weight becomes stronger with age, ${ }^{4}$ which can be explained by longer duration of smoking. ${ }^{516}$

Among smokers a U-shaped relationship between the number of cigarettes smoked and relative body weight has been found in several studies-those smoking 10-20 cigarettes per day being the leanest. ${ }^{1-5791718}$ Although this seems paradoxical given the metabolic effects of smoking, it has been suggested that heavy smokers may weigh more because of clustering of other unhealthy habits such as high intake of saturated fat, heavy use of alcohol, and little exercise. Indeed, a study in Finland found that a change in the association between smoking and body weight had occurred in the 1980ssmoking was no longer associated with leanness in this population but rather it was positively related to BMI, especially among younger middle aged men. ${ }^{16}$

Most studies of the relationship between smoking and relative body weight have looked at single populations or cohorts. Therefore we considered it important to examine whether associations are similar in populations with different histories of smoking habits and changes in body weight. We investigated this among men and women in 42 populations participating the WHO MONICA Project.

Given the findings of the Finnish study on changes in the relationship between smoking and relative body weight, it could be hypothesised that the "classical" inverse association between smoking and relative body weight might hold in populations with a high prevalence of smoking and comparatively few anti-smoking activities, while a "new" positive association between smoking and relative body weight may be more typical in populations with a previously high but currently falling prevalence of smoking due to anti-smoking programmes. While our data do not allow us to test this hypothesis directly, we will mainly focus on determining whether there are populations with the "new" association to warrant pursuing such a hypothesis.

\section{Methods}

The WHO MONICA Project was designed to measure trends in the incidence in and mortality from cardiovascular disease, and to assess the extent to which these trends are related to changes in known risk factors in 49 study populations in 26 countries. Risk factors in the WHO MONICA Project are monitored through up to three independent cross sectional population surveys. ${ }^{1920}$ The surveys included random samples of at least 200 people in each gender and 10 year age group, for the age range 35-64 years, and optionally $25-34$ years. This study presents data from the baseline surveys. The survey periods range from May 1979 to February 1989 and are mostly concentrated in the early and mid 1980s. In this study, only the age range from $35-64$ years is considered. The overall participation rates for the surveys varied from $54 \%-89 \%$. The population sizes, 
participation rates, and survey periods have been described in more detail elsewhere. ${ }^{21}$

Height and body weight were measured with participants standing without shoes and heavy outer garments. Body mass index (BMI) was calculated as weight divided by height squared $\left(\mathrm{kg} / \mathrm{m}^{2}\right)$ as a measure for relative weight. BMI categories were formed according to the WHO guidelines, ${ }^{22}$ except for using $21 \mathrm{~kg} / \mathrm{m}^{2}$ instead of the WHO recommendation of $18 \mathrm{~kg} / \mathrm{m}^{2}$ as a cut off point for the leanest category. This cut off point was selected to ensure a sufficient number of subjects in each category and because of its use in some other studies. ${ }^{23}$ The subjects were classified as follows:

- Lean persons-BMI less than $21 \mathrm{~kg} / \mathrm{m}^{2}$

- Persons of normal weight-BMI equal to or more than 21 but less than $25 \mathrm{~kg} / \mathrm{m}^{2}$

- Overweight persons-BMI equal to or more than 25 but less than $30 \mathrm{~kg} / \mathrm{m}^{2}$

- Obese persons-BMI equal to or more than $30 \mathrm{~kg} / \mathrm{m}^{2}$

Data on smoking were obtained with a standard questionnaire. ${ }^{24}$ In the analysis respondents were classified as follows:

- Regular cigarette smokers, those reporting smoking cigarettes every day. They were further classified in concordance with several other studies ${ }^{2389}$ as (a) light to moderate smokers, those smoking 1-19 cigarettes per day, and (b) heavy smokers, those smoking 20 or more cigarettes per day.

- Other current smokers, those reporting smoking cigarettes occasionally, or at least $1 \mathrm{~g}$ of pipe tobacco per week, or at least one cigar per week.

- Ex-smokers, those reporting smoking cigarettes regularly in the past but not currently.

- Never smokers, those who were not current smokers and had never smoked cigarettes regularly.

The age group of the subject was obtained from the sampling frame at the time of sample selection. Tertiles of years of schooling within each population were used as a measure of socioeconomic status (SES). Years of schooling were obtained by asking - "How many years did you spent at school or in full-time study?". Tertiles of years of schooling were calculated for men and women in each 10 year age group separately.

\section{KEY POINTS}

- Cigarette smokers are leaner than never smokers in most of the populations studied - and more so in women than men.

- In some populations there was no association between smoking and body weight. In these populations, among men, there were fewer smokers and more ex-smokers than in populations in which smokers were leaner than never smokers.

- Ex-smoking men weighed on average more than never smokers, whereas in women no consistent pattern was found.
The quality of data on weight, height, smoking behaviour, and years of schooling has been centrally assessed. Any population with an unsatisfactory quality of data or response rate lower than $50 \%$ for any of the items has been omitted from this study. This left 42 populations, except for analyses involving years of schooling, where only a subset of 34 populations with full data was included.

\section{STATISTICAL METHODS}

In the first phase of data analysis, population level (ecological) data were analysed to estimate the strength of association between smoking and relative body weight. Pearson correlation coefficients between the proportions of regular cigarette smokers and the means and centiles of BMI were calculated for men and women for each 10 year age group. Correlations of age standardised values are given for the age group 35-64. Age standardised values were calculated using the world standard population, ${ }^{25}$ as the reference population with weights 12,11 , and 8 for the 10 year age groups $35-44,45-54$, and $55-64$ respectively.

In the second phase, individual data were used to examine the consistency and magnitude of the relation between smoking and BMI at the individual level. All analyses were carried out separately for men and women. Two types of analyses were performed-firstly, comparing medians or means of BMI between different categories of smoking, and secondly, comparing proportions of regular smokers between different categories of BMI within populations. Differences were reported to be statistically significant if the $\mathrm{p}$ value was less than 0.05 .

To compare the levels of BMI between smoking categories, medians instead of means of BMI were used because of the distributions of BMI were skewed to the right. Confidence intervals for the differences in median BMIs in categories of smokers, compared with the never smoker category, were calculated using the Normal approximation as described by White et al. ${ }^{26}$ Linear regression was used to control for potential confounding by SES. Mean BMIs and differences in mean BMIs in relation to smoking category were calculated using the general linear model (GLM) procedure of $S A S$ statistical software,${ }^{27}$ adjusting for age group and population as categorical covariates. To assess the confounding effect of SES, regression analyses were performed both with and without adjusting for population specific tertiles of years of schooling. Confidence intervals for the estimates were calculated from the standard errors of the regression coefficients assuming that the sampling distributions of the coefficients were normal. The results of the linear regression were also used to give an overall estimate of the differences in the mean BMIs between smoking categories, summarising the results across all populations. In addition, the same overall estimates were calculated using non-parametric methods to confirm that the estimates based on the regression analysis did not differ from the estimates based on medians. 
Table 1 Number of subjects, age standardised proportion (\%) of regular cigarette smokers, and age standardised prevalence of obesity (BMI $\geq 30$ kg/ $m^{2}$ ) in first MONICA population survey. Men and women aged 35-64 years

\begin{tabular}{|c|c|c|c|c|c|c|c|c|}
\hline \multirow[b]{2}{*}{ Population } & \multirow[b]{2}{*}{ Country } & \multirow[b]{2}{*}{ Abbreviation } & \multicolumn{3}{|l|}{ Men } & \multicolumn{3}{|c|}{ Women } \\
\hline & & & No & Smokers \% & Obese \% & No & Smokers \% & Obese\% \\
\hline Newcastle & Australia & AUS-NEW & 1218 & 34 & 15 & 1241 & 24 & 16 \\
\hline Perth & Australia & AUS-PER & 631 & 33 & 9 & 661 & 22 & 11 \\
\hline Ghent & Belgium & BEL-GHE & 539 & 43 & 11 & 495 & 25 & 15 \\
\hline Luxembourg Province & Belgium & BEL-LUX & 989 & 43 & 13 & 959 & 18 & 18 \\
\hline Beijing & China & CHN-BEI & 619 & 51 & 3 & 641 & 16 & 9 \\
\hline Czech Republic & Czech Rep. & CZE-CZE & 948 & 44 & 21 & 990 & 21 & 32 \\
\hline Glostrup & Denmark & DEN-GLO & 1456 & 45 & 11 & 1361 & 44 & 10 \\
\hline Kuopio Province & Finland & FIN-KUO & 968 & 34 & 18 & 981 & 10 & 19 \\
\hline North Karelia & Finland & FIN-NKA & 1125 & 30 & 17 & 1212 & 9 & 24 \\
\hline Turku/Loimaa & Finland & FIN-TUL & 1194 & 30 & 19 & 1270 & 17 & 17 \\
\hline Lille & France & FRA-LIL & 641 & 39 & 14 & 530 & 11 & 19 \\
\hline Strasbourg & France & FRA-STR & 666 & 34 & 22 & 714 & 14 & 23 \\
\hline Toulouse & France & FRA-TOU & 678 & 36 & 9 & 645 & 17 & 11 \\
\hline Augsburg rural & Germany & GER-AUR & 846 & 30 & 20 & 857 & 12 & 22 \\
\hline Augsburg urban & Germany & GER-AUU & 712 & 36 & 18 & 679 & 18 & 15 \\
\hline Bremen & Germany & GER-BRE & 633 & 45 & 14 & 656 & 29 & 18 \\
\hline Cottbus County & Germany & GER-COT & 460 & 31 & 17 & 543 & 11 & 23 \\
\hline Halle County & Germany & GER-HAC & 816 & 38 & 18 & 859 & 14 & 27 \\
\hline Karl-Marx-Stadt County & Germany & GER-KMS & 813 & 37 & 14 & 926 & 15 & 19 \\
\hline Rest of DDR-MONICA & Germany & GER-RDM & 763 & 37 & 17 & 822 & 24 & 21 \\
\hline Rhein-Neckar Region & Germany & GER-RHN & 1170 & 31 & 13 & 1266 & 23 & 12 \\
\hline Iceland & Iceland & ICE-ICE & 657 & 26 & 11 & 704 & 40 & 11 \\
\hline Area Brianza & Italy & ITA-BRI & 618 & 44 & 11 & 639 & 18 & 15 \\
\hline Friuli & Italy & ITA-FRI & 719 & 35 & 16 & 724 & 26 & 19 \\
\hline Kaunas & Lithuania & LTU-KAU & 728 & 38 & 22 & 735 & 4 & 45 \\
\hline Auckland & New Zealand & NEZ-AUC & 1018 & 29 & 8 & 567 & 25 & 9 \\
\hline Tarnobrzeg Voivodship & Poland & POL-TAR & 1250 & 58 & 13 & 1472 & 11 & 32 \\
\hline Warsaw & Poland & POL-WAR & 1309 & 59 & 18 & 1337 & 33 & 26 \\
\hline Bucharest & Romania & ROM-BUC & 524 & 38 & 20 & 632 & 15 & 31 \\
\hline Moscow control & Russia & RUS-MOC & 770 & 48 & 13 & 645 & 12 & 33 \\
\hline Moscow intervention & Russia & RUS-MOI & 1163 & 46 & 12 & 1234 & 9 & 35 \\
\hline Novosibirsk control & Russia & RUS-NOC & 1061 & 59 & 15 & 1054 & 3 & 44 \\
\hline Novosibirsk interv. & Russia & RUS-NOI & 601 & 53 & 13 & 646 & 3 & 43 \\
\hline Catalonia & Spain & SPA-CAT & 993 & 47 & 9 & 994 & 7 & 24 \\
\hline Gothenburg & Sweden & SWE-GOT & 517 & 33 & 7 & 557 & 34 & 9 \\
\hline Northern Sweden & Sweden & SWE-NSW & 640 & 24 & 11 & 611 & 26 & 14 \\
\hline Ticino & Switzerland & SWI-TIC & 781 & 38 & 20 & 769 & 24 & 15 \\
\hline Vaud/Fribourg & Switzerland & SWI-VAF & 627 & 32 & 13 & 568 & 21 & 13 \\
\hline Belfast & UK & UNK-BEL & 927 & 34 & 11 & 925 & 33 & 14 \\
\hline Glasgow & UK & UNK-GLA & 502 & 52 & 11 & 480 & 50 & 16 \\
\hline Stanford & USA & USA-STA & 427 & 40 & 10 & 516 & 36 & 15 \\
\hline Novi Sad & Yugoslavia & YUG-NOS & 592 & 49 & 17 & 555 & 27 & 29 \\
\hline
\end{tabular}
Table 2 Pearson correlation coefficients between the proportion (\%) of regular cigarette
smokers and mean and centiles of body mass index (BMI) for 42 populations in the first MONICA survey

\begin{tabular}{|c|c|c|c|c|}
\hline \multirow[b]{2}{*}{ Age group } & \multicolumn{2}{|l|}{ Men } & \multicolumn{2}{|l|}{ Women } \\
\hline & $r$ & $(95 \% C I)$ & $r$ & $(95 \% C I)$ \\
\hline $\begin{array}{l}\text { Mean } \\
35-44 \\
45-54 \\
55-64 \\
\text { Age standardised } \\
35-64 \\
\text { Median } \\
35-44 \\
45-54 \\
55-64 \\
\text { Age standardised } \\
35-64 \\
10 \text { th centile } \\
35-44 \\
45-54 \\
55-64 \\
\text { Age standardised } \\
35-64 \\
90 \text { th centile } \\
\text { 35-44 } \\
\text { 45-54 } \\
55-64 \\
\text { Age standardised } \\
\text { 35-64 } \\
\end{array}$ & $\begin{array}{r}-0.07 \\
-0.37 \\
-0.30 \\
-0.25 \\
\\
0.00 \\
-0.34 \\
-0.30 \\
-0.22 \\
-0.16 \\
-0.54 \\
-0.50 \\
-0.43 \\
0.04 \\
-0.22 \\
-0.10 \\
-0.08 \\
\end{array}$ & $\begin{array}{l}(-0.36,0.24) \\
(-0.61,-0.08) \\
(-0.55,0.01) \\
(-0.52,0.05) \\
(-0.30,0.30) \\
(-0.59,-0.04) \\
(-0.55,0.00) \\
(-0.49,0.09) \\
(-0.44,0.15) \\
(-0.73,-0.29) \\
(-0.70,-0.23) \\
(-0.65,-0.14) \\
(-0.27,0.34) \\
(-0.49,0.09) \\
(-0.39,0.21) \\
(-0.37,0.23) \\
\end{array}$ & $\begin{array}{r}-0.45 \\
-0.65 \\
-0.63 \\
-0.59 \\
-0.46 \\
-0.62 \\
-0.64 \\
-0.57 \\
-0.47 \\
-0.63 \\
-0.58 \\
-0.56 \\
-0.37 \\
-0.58 \\
-0.60 \\
-0.54 \\
\end{array}$ & $\begin{array}{l}(-0.66,-0.17) \\
(-0.79,-0.43) \\
(-0.79,-0.41) \\
(-0.76,-0.35) \\
(-0.67,-0.18) \\
(-0.78,-0.39) \\
(-0.79,-0.41) \\
(-0.75,-0.33) \\
(-0.68,-0.19) \\
(-0.79,-0.41) \\
(-0.75,-0.33) \\
(-0.74,-0.31) \\
(-0.61,-0.08) \\
(-0.75,-0.33) \\
(-0.76,-0.36) \\
(-0.72,-0.28)\end{array}$ \\
\hline
\end{tabular}

age group as the independent variable, with and without adjustment for indicator variables for BMI categories.

To estimate the overall difference in the age standardised proportions of regular cigarette smokers between BMI categories, the mean of the differences and a $95 \%$ confidence interval for this mean were calculated, summarising the results across all study populations. The normal weight category $\left(B M I=21.0-24.9 \mathrm{~kg} / \mathrm{m}^{2}\right)$ was used as the reference category when comparing proportions of regular smokers. The confidence intervals were calculated from standard errors of the means using $t$ distribution with the number of populations minus one for the degrees of freedom.

\section{Results}

Table 1 gives the number of subjects, age standardised proportion of regular cigarette smokers and age standardised prevalence of obesity $\left(B M I \geq 30 \mathrm{~kg} / \mathrm{m}^{2}\right)$ in each population. The table shows considerable variation both in the prevalence of regular smoking and obesity across the study populations. The prevalence of regular cigarette smoking ranged from $24 \%-59 \%$ in men and from $3 \%-50 \%$ in women. In general, among men the prevalence of smoking was highest in some eastern European (Poland, Russia) populations and lowest in some Nordic (Sweden, Iceland) populations. Among women, however, smoking was relatively more common in some western European popu- 

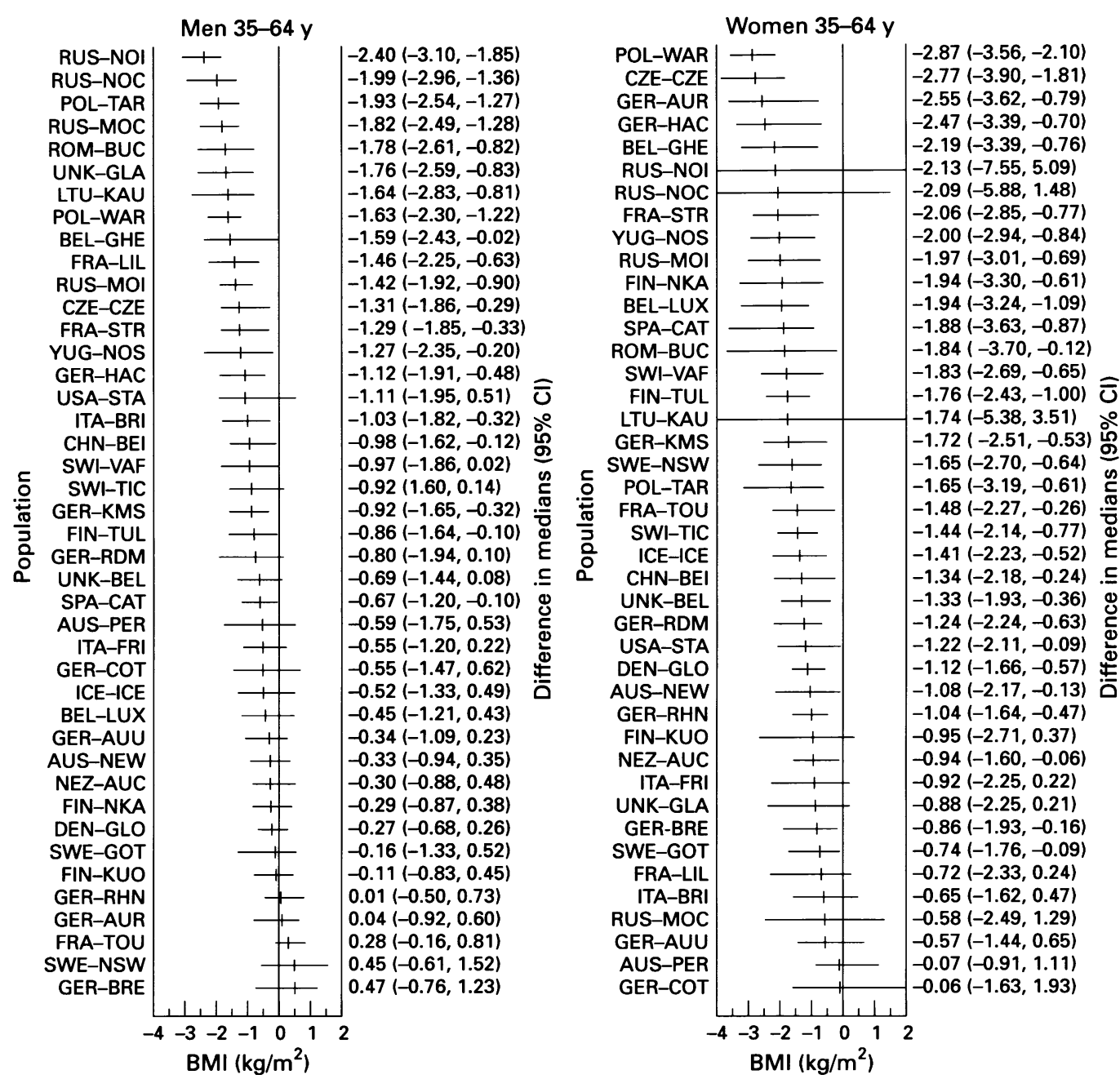

Figure 1 Difference in median BMI between regular cigarette smokers and never smokers in the first MONICA survey. Left, men aged 35-64; right, women aged 35-64.

lations and less common in eastern Europe. There were more female than male smokers only in Iceland (where $22 \%$ of men smoked pipes or cigars) and in Sweden. The prevalence of obesity ranged from $3 \%-22 \%$ in men and from $9 \%-45 \%$ in women and was relatively more common in populations with a low prevalence of smoking, especially among women.

Table 2 presents Pearson correlation coefficients between the proportion of regular cigarette smokers and BMI. These are ecological correlations where each population represents one observation. For women, smoking was significantly inversely related to $\mathrm{BMI}$ for all four measures - 10th centile (leanness), mean and median BMI (average weight) or 90th centile (obesity). For men, the age standardised prevalence of smoking was significantly inversely related to the 10 th centile only. For both men and women the weakest correlations were observed in the age group 35-44 years.

Figure 1 shows differences in median BMI between never smokers and regular cigarette smokers. In almost all populations smokers were leaner than never smokers-the difference was statistically significant in 20 out of 42 populations for men and in 30 out of 42 populations for women. The differences ranged from -2.4 to $0.5 \mathrm{~kg} / \mathrm{m}^{2}$ in men and from -2.9 to
$-0.1 \mathrm{~kg} / \mathrm{m}^{2}$ in women. When translated into $\mathrm{kg}$ for average heights of $1.72 \mathrm{~m}$ and $1.60 \mathrm{~m}$ for men and women respectively, they correspond to the range from -7.1 to $1.5 \mathrm{~kg}$ for men and from -7.4 to $-0.3 \mathrm{~kg}$ for women. The largest differences were observed in populations with relatively high smoking rates (eg in some eastern European populations).

To elucidate further the difference between the populations where the smokers were considerably leaner than never smokers in comparison to populations where they were not, we compared the proportion of regular smokers in the 14 populations with the largest differences in BMI to the 14 populations with the smallest differences in BMI between smokers and never smokers with a non-parametric (Wilcoxon rank sum) test (table 3). Among men, there were significantly more regular smokers in the populations with the largest differences in BMI than in the populations with the smallest differences. In addition, the proportions of exsmokers were statistically significantly lower in these populations. For women, however, there were fewer smokers in the group of populations with the largest differences in BMI than in the populations with the smallest differences but the difference in smoking prevalences was not statistically significant. The prevalence of ex- 
Table 3 Proportions of regular smokers and ex-smokers in 14 populations with the largest difference in BMI between smokers and never smokers compared with 14 populations with the smallest difference. First MONICA survey, men and women aged 35-64

\begin{tabular}{|c|c|c|c|c|c|c|}
\hline & $\begin{array}{l}\text { Range for difference in BMI between } \\
\text { smokers and never smokers }\left(\mathrm{kg} / \mathrm{m}^{2}\right)\end{array}$ & $\begin{array}{l}\text { Median \% of } \\
\text { regular smokers }\end{array}$ & p value & $\begin{array}{l}\text { Median \% of } \\
\text { ex-smokers }\end{array}$ & $p$ value & No \\
\hline $\begin{array}{l}\text { Men } \\
\text { Largest difference }\end{array}$ & $-2.4,-1.3$ & 47 & \multirow{2}{*}{$<0.001$} & 23 & \multirow{2}{*}{0.03} & 14 \\
\hline Smallest difference & $-0.5,0.5$ & 33 & & 29 & & 14 \\
\hline $\begin{array}{l}\text { Women } \\
\text { Largest difference }\end{array}$ & $-2.9,-1.8$ & 14 & \multirow{2}{*}{0.07} & 7 & \multirow{2}{*}{0.02} & 14 \\
\hline Smallest difference & $-1.1,-0.1$ & 22 & & 10 & & 14 \\
\hline
\end{tabular}

smokers was significantly lower in the populations with large differences in BMI.

Figure 2 shows the difference in median BMI between never smokers and ex-smokers. Exsmokers had higher BMI than never smokers in 37 (and significantly so in 10) out of 42 populations among men, whereas for women there were differences in both directions but few were statistically significant. No systematic differences in BMI were observed between heavy and light smokers in most populations (data not shown).

Regression analysis was used to examine the potential confounding effects of SES using population specific tertiles of years of schooling as an indicator. The unadjusted (for SES) ana- lysis was performed first for all populations and then for a subset of 34 populations, for which data on years of schooling were available, and then the SES adjusted analysis was performed for the 34 populations (table 4). The results were very similar whether adjusted for tertiles of years of schooling or not, indicating that SES had hardly any confounding effect on this association.

The mean BMI in the never smoking category was $26.6 \mathrm{~g} / \mathrm{m}^{2}$ for men and $26.8 \mathrm{~kg} / \mathrm{m}^{2}$ for women when adjusted for age group and population. In men, regular cigarette smokers were on average $0.9 \mathrm{~kg} / \mathrm{m}^{2}$ leaner than never smokers, which implies that a male smoker of average height of $1.72 \mathrm{~m}$ weighed $2.7 \mathrm{~kg}$ less
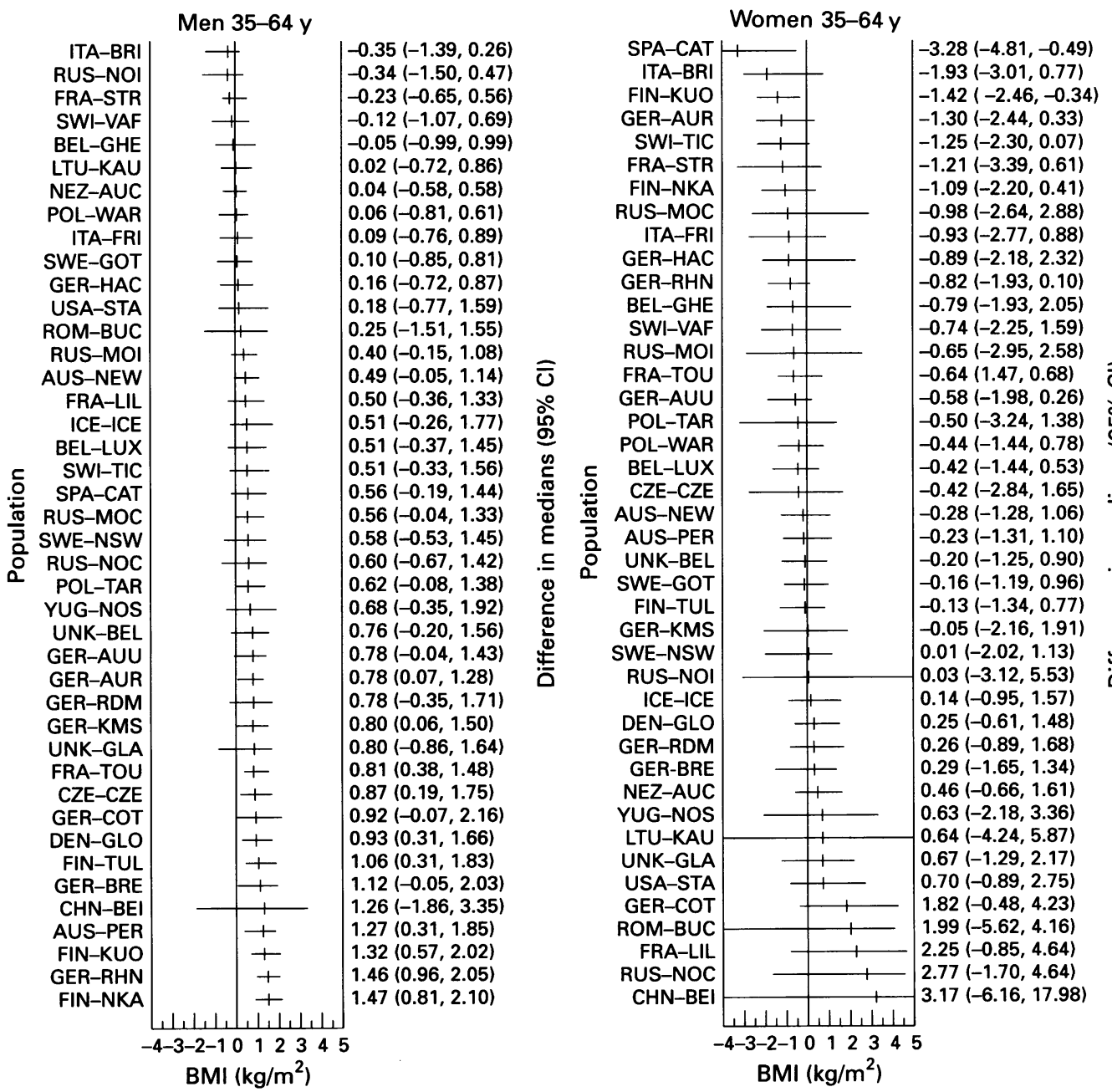

Figure 2 Difference in median BMI b
aged 35-64; right, women aged 35-64. 
Table 4 Summary measures of BMI in relation to smoking category. Results from regression analysis. First MONICA survey, men and women aged 35-64

\begin{tabular}{|c|c|c|c|}
\hline & \multicolumn{3}{|c|}{ Mean BMI (95\% CI) adjusted for age group and population } \\
\hline & Unadjusted for SES* & Unadjusted for SES† & Adjusted for SES† \\
\hline $\begin{array}{l}\text { Men } \\
\text { Never smokers }\end{array}$ & $26.6(26.5,26.6)$ & $26.6(26.5,26.7)$ & $26.6(26.5,26.7)$ \\
\hline $\begin{array}{l}\text { Difference between never smokers and } \\
\text { Regular cigarette smokers } \\
\text { Light smokers } \\
\text { Heavy smokers } \\
\text { Ex-smokers }\end{array}$ & $\begin{array}{l}-0.9(-1.0,-0.8) \\
-0.9(-1.0,-0.7) \\
-0.9(-1.0,-0.7) \\
0.5(0.4,0.6)\end{array}$ & $\begin{array}{l}-0.9(-1.0,-0.8) \\
-0.9(-1.0,-0.8) \\
-0.9(-1.1,-0.8) \\
0.5(0.4,0.6)\end{array}$ & $\begin{array}{l}-1.0(-1.1,-0.9) \\
-0.9(-1.1,-0.8) \\
-1.0(-1.1,-0.9) \\
0.5(0.4,0.6)\end{array}$ \\
\hline $\begin{array}{l}\text { Women } \\
\text { Never smokers }\end{array}$ & $26.8(26.7,26.9)$ & $26.9(26.9,27.0)$ & $26.9(26.8,26.9)$ \\
\hline $\begin{array}{l}\text { Difference between never smokers and } \\
\text { Regular cigarette smokers } \\
\text { Light smokers } \\
\text { Heavy smokers } \\
\text { Ex-smokers }\end{array}$ & $\begin{array}{l}-1.1(-1.3,-1.0) \\
-1.3(-1.4,-1.1) \\
-0.8(-1.0,-0.6) \\
-0.03(-0.2,0.2)\end{array}$ & $\begin{array}{l}-1.2(-1.4,-1.1) \\
-1.4(-1.5,-1.2) \\
-0.9(-1.1,-0.7) \\
-0.05(-0.3,0.2)\end{array}$ & $\begin{aligned}-1.2(-1.3,-1.0) \\
-1.3(-1.5,-1.1) \\
-0.9(-1.1,-0.7) \\
0.1(-0.1,0.3)\end{aligned}$ \\
\hline
\end{tabular}

Socioeconomic status (SES) measured with population, gender, and age group specific tertiles of years of schooling

* Based on data from 42 populations

+ Based on data from 34 populations

than a never smoker of the same height. Male ex-smokers had $0.5 \mathrm{~kg} / \mathrm{m}^{2}$ higher BMI than never smokers indicating that an ex-smoker of average height weighed $1.5 \mathrm{~kg}$ more than never smoker. In women, regular cigarette smokers were on average $1.1 \mathrm{~kg} / \mathrm{m}^{2}$ leaner than never smokers which implies a difference of $2.8 \mathrm{~kg}$ for a woman of average height of $1.60 \mathrm{~m}$, but there was no significant difference between never and ex-smokers. For women, but not for men, light smokers had significantly lower BMIs than heavy smokers thus showing a Ushaped relationship between smoking and BMI.

The overall estimates of the differences in BMI between smoking categories were also calculated using non-parametric methods. The estimates based on medians were very similar to those produced by the regression analysis. Only the median BMIs for never smokers $\left(26.3\right.$ and $26.1 \mathrm{~kg} / \mathrm{m}^{2}$ for men and women respectively) were somewhat lower than the means, especially for women, due to the skewness of the distributions.

The age standardized proportion of regular smokers decreased consistently with increasing BMI category (table 5). The difference between BMI categories was significant in 35 out of 42 populations among men and in 26 among women. In men the differences were larger than in women. Some exceptions to the general pattern were observed, for example among men in Auckland, Gothenburg, Toulouse, and northern Sweden there were more smokers in the obese than in the normal weight category,

Table 5 Age standardised prevalence of regular cigarette smoking in relation to BMI category based on data from 42 populations. First MONICA survey, men and women aged 35-64

\begin{tabular}{lll}
\hline BMI category & Proportion (\%) of smokers & $95 \% \mathrm{CI}$ \\
\hline Men & & \\
Lean $(\mathrm{BMI}<21.0)$ & 61.8 & $(56.4,67.2)$ \\
Normal weight $(\mathrm{BMI}=21.0-24.9)$ & 45.6 & $(41.8,49.3)$ \\
Overweight $(\mathrm{BMI}=25.0-29.9)$ & 35.2 & $(32.8,37.6)$ \\
Obese (BMI>=30.0) & 31.8 & $(29.5,34.1)$ \\
Women & & \\
Lean (BMI<21.0) & 30.0 & $(26.0,34.0)$ \\
Normal weight $(\mathrm{BMI}=21.0-24.9)$ & 22.8 & $(19.3,26.4)$ \\
Overweight $(\mathrm{BMI}=25.0-29.9)$ & 18.0 & $(14.8,21.2)$ \\
Obese $(\mathrm{BMI}=30.0)$ & 13.9 & $(11.3,16.5)$ \\
\hline
\end{tabular}

but the exceptions were usually not statistically significant.

On the basis of these results one could group the populations into two categories. In most populations for men and almost all for women the "classic" inverse association between smoking and BMI was observed. In some populations, there was no clear association. These include at least Auckland, Gothenburg, Toulouse, and northern Sweden for men and perhaps Cottbus County and Perth for women.

\section{Discussion}

The association between smoking and relative body weight is an important health issue because both smoking and increased body weight are independent risk factors for cardiovascular disease and quitting smoking is known to lead to weight gain. In addition, smoking is a potential confounder in the relationship between relative body weight and mortality. ${ }^{823}$ Therefore the recent suggestion that the relationship might be changing from a negative association to a positive one, ${ }^{16}$ especially among men, prompted us to explore this association in a wide range of populations. The data collected through the WHO MONICA project population surveys provided a unique opportunity to look at this relationship in a large number of populations from different parts of the world, based on common standardised survey methods for data collection and quality assurance, and centralised data analysis.

Our results show that the generally accepted finding that smokers weigh less than never smokers. ${ }^{12}$ still prevails in most populations. This was especially true for women. Also, a Ushaped relationship between BMI and number of cigarettes smoked was found among women but not among men, whereas earlier investigations have generally found a stronger relationship in men. ${ }^{491618}$ This could be partly explained by the fact that we only used two categories for numbers of cigarettes smoked.

Among men, in some of the study populations there was no association between smoking and BMI and in these populations there 
were in general fewer smokers and more exsmokers than in populations where smokers were considerably leaner than never smokers. This finding suggests that the magnitude of the inverse association between smoking and body weight may be related to the prevalence of smoking in the population. It also partly supports the original hypothesis that the "classical" inverse association might no longer be found in populations with extensive anti-smoking activities and reduced prevalence of smoking, eg in Australia, Finland, Sweden, the USA. However, no statistically significant positive association was found in any of these populations. Therefore it would be premature to draw any definitive conclusions about a change in the direction of the relationship, especially because this study was based on cross sectional data and reflects the situation in the early and mid 1980s. More recent data, covering a longer time period, will allow this hypothesis to be tested directly.

One mechanism by which the change from inverse to positive correlation between smoking and BMI observed in the Finnish study, ${ }^{16}$ might act is through selection among smokers. As an increasing proportion of light smokers tend to quit smoking when smoking becomes regarded as socially undesirable behaviour, the group of smokers consists increasingly of heavy smokers, who on one hand have more difficulties in quitting, ${ }^{17}$ and who on the other hand have higher BMIs than light smokers. ${ }^{13917}$ The change in the association from inverse to positive would therefore be only an ecological change at the population level since the relative body weight of the heavy smokers at individual level need not have changed. The lack of an inverse association between smoking and BMI is more often seen among younger men than among older men or women. This might be partly explained because the decline in body weight is a long term affect of smoking, whereas the slightly higher BMI observed in heavy smokers may be unrelated to the duration of smoking. This is, in fact, in agreement with the findings of the Finnish study where, in spite of the overall positive association, years of smoking was confirmed as a significant inverse predictor of BMI. ${ }^{16}$ The effect of duration of smoking on body weight can however be an indirect one; it is better recognised in older people whose weights have a bigger range than in the young. The reasons for higher BMI of heavy smokers remain unclear. Clustering of unhealthy habits, ${ }^{16}$ and use of smoking as a way to control body weight among obese people, ${ }^{4}$ have been suggested as potential explanations, but no studies have been conducted specifically to explore this phenomenon.

When looking at the prevalence of smoking between different BMI categories, the most consistent inverse association was found in relation to leanness, especially among men. This is supported by earlier research, ${ }^{8}$ and suggests that even if, in some populations, average body weight might be positively associated with smoking, leanness remains inversely associated with cigarette smoking. Our data did not allow us to investigate the association between BMI and duration of smoking. This might have further elucidated the differences between populations, because mean age of starting to smoke may differ among populations and this, too, could affect the distribution of BMI.

Some studies have found ex-smokers to be heavier than never smokers, ${ }^{410}$ whereas others have not. ${ }^{35}$ Our findings suggest that, among men, ex-smokers tend to have higher BMI than never smokers, but not among women and this finding is supported by one earlier study. ${ }^{11}$ Also Flegal et $a l,{ }^{14}$ found that male ex-smokers were heavier than never smokers, but among women only those ex-smokers who had stopped smoking less than 10 years ago were heavier. The category of occasional cigarette smokers, pipe, and cigar smokers was not compared with never smokers in this study because of the small number of observations.

Socioeconomic status (SES) is a potential confounder in the relationship between smoking and body weight. Persons with lower SES tend to smoke more, ${ }^{928}$ and to have higher BMIs, ${ }^{911} 18$ than those with higher SES, the latter especially among women. The associations found in this study were not explained by the effects of SES measured in tertiles of years of schooling. This is consistent with the results of several other studies. ${ }^{35918}$ We did not measure such potential confounders as physical activity, caloric intake, and alcohol use, but in several studies they have not been found to be actual confounders, ${ }^{3518}$ for the BMI-smoking relationship.

This work is one example how large international multi-centre studies can be used to obtain an overview strengthened by standardised methods of data collection and quality assurance. One should, however, be cautious in applying quantitative measures obtained by combining data from heterogenous populations. Nevertheless, the consistency of associations observed among a large number of different populations gives considerably more weight to the findings than results based only on one cohort or study population which cannot be directly generalised to other populations.

In summary, in populations of the WHO MONICA project covering a wide range of smoking habits and prevalence of overweight, men and women who smoked generally had lower BMIs than never smokers. Among men, the difference was more pronounced in populations where smoking was relatively more common. Heavy smokers did not generally have lower BMIs than light smokers. Among men, but not among women, those who had stopped smoking had higher BMIs than those who never smoked. These results confirm that smoking is associated with relative body weight in individuals as well as in populations but that differences in smoking habits in a population can influence the magnitude of this association.

Funding: MONICA Centres are funded predominantly by regional and national governments, research councils, and research charities. Coordination is the responsibility of the World Health Organization (WHO), assisted by local fund raising fo congresses and workshops. WHO also supports the MONICA Data Centre (MDC) in Helsinki. Not covered by this genera description is the ongoing generous support of the MDC by the National Public Health Institute of Finland, and a contribution to WHO from the National Heart, Lung, and Blood 
Institute, National Institutes of Health, Bethesda, Maryland, USA for support of the MDC.

Conflicts of interest: none.

1 Khosla T, Lowe CR. Obesity and smoking habits. BMF 1971;4:10-13.

2 Gordon T, Kannel WB, Dawber TR, McGee D. Changes associated with quitting cigarette smoking: the Framingham study. Am Heart f 1975;90:322-28.

3 Noppa $\mathrm{H}$, Bengtsson $\mathrm{C}$. Obesity in relation to smoking: a population study of women in Göteborg, Sweden. Prev Med 1980;9:534-43.

4 Jacobs DR Jr, Gottenborg S. Smoking and weight: the Minnesota Lipid Research Clinic. Am $\mathcal{f}$ Public Health 1981;71:391-96.

5 Albanes D, Jones DY, Micozzi MS, Mattson M. Associations between smoking and body weight in the U.S. population-analysis of NHANES II. Am 7 Public Health 1987; 77:439-44.

6 Kromhout D, Saris WH, Horst CH. Energy intake, energy expenditure and smoking in relation to body fatness: the expenditure and smoking in relation to body fatness

7 Shimokata H, Muller DC, Andres R. Studies in the dis tribution of body fat: effects of cigarette smoking. $¥ A M A$ 1989;261:1169-73.

8 Wannamethee G, Shaper AG. Body weight and mortality in middle aged British men: impact of smoking. $B M F$ 1989;299:1497-502.

9 Istvan JA, Cunningham TW, Garfinkel L. Cigarette smoking and body weight in the Cancer Prevention Study I. Int $\mathcal{F}$ Epidemiol 1992;21: 849-53.

10 Chen Y, Horne SL, Dosman JA. The influence of smoking cessation on body weight may be temporary. Am $\mathcal{F}$ Public Health 1993;83:1330-32.

11 Boyle CA, Dobson AJ, Egger G, Magnus P. Can the increasing weight of Australians be explained by the decreasing prevalence of cigarette smoking? Int $f$ Obes 1994; 18:55-60.

12 Grunberg NE. Smoking cessation and weight gain. $N$ Engl 7 Med 1991;324:768-69.

13 Williamson DF, Madans J, Anda RF, Kleinman JC, Giovino GA, Byers T. Smoking cessation and severity of weight gain in a national cohort. N Engl f Med 1991;324: 739-45.

14 Flegal KM, Troiano RP, Pamuk ER, Kuczmarski RJ, Campbell SM. The influence of smoking cessation on the prevalence of overweight in the United States. $N$ Engl $\mathcal{F}$ Med 1995;333:1165-70.

15 Hofstetter A, Schultz Y, Jequier E, Wahren J. Increased 24hour energy expenditure in cigarette smokers. $N$ Engl $\mathcal{f}$ Med 1986;314:79-82.

16 Marti B, Tuomilehto J, Korhonen HJ, Kartovaara L, Vartiainen E, Pietinen $\mathrm{P}$ et al. Smoking and leanness: evidence for change in Finland. BMF 1989;298:1287-90.

17 Killen JD, Fortmann SP, Telch MJ, Newman B. Are heavy smokers different from light smokers? A comparison after 48 hours without cigarettes. $\mathfrak{F A M} A$ 1988;260:1581-85.

18 Istvan JA, Nides MA, Buist AS, Greene P, Voelker H Salivary cotinine, frequency of cigarette smoking, and Salivary cotinine, frequency of cigarette smoking, and body mass index: findings at baseline in the

19 WHO MONICA Project Principal Investigators. The World Health Organization MONICA Project (monitoring trends and determinants in cardiovascular disease): A major international collaboration. F Clin Epidemiol 1988; 41:105-14

20 World Health Organization. MONICA manual. Version 1.1. December 1986, CVD/MNC. Geneva, World Health Organization, 1986

21 WHO MONICA Project prepared by Keil U, Kuulasmaa K. WHO MONICA project: risk factors. Int $f$ Epidemiol 1989;18 (Suppl 1):S46-S55. Erratum, Int $\mathcal{F}$ Epidemiol 1990;19:776

22 WHO Expert Committee. Physical status: the use and interpretation of anthropometry. Technical Report Series no 854. Geneva: WHO, 1995 .

23 Manson JE, Colditz GA, Stampfer MJ, Willett WC, Rosner $\mathrm{B}$, Monson RR et al. A prospective study of obesity and risk of coronary heart disease in women. $N$ Engl $\mathcal{f}$ Med

24 Rose GA, Blackburn H, Gillum RF, Prineas RJ. Cardiovascular survey methods. Geneva:World Health Organization, 1982

25 Waterhouse J, Muir CS, Correa P, Powell J, eds. Cancer incidence in five continents. Lyon:IARC, 1976; 456.

26 White IR, Chaturvedi N, McKeigue PM. Median analysis of blood pressure for a sample including treated hypertensives. Stat Med 1994;13:1635-41.

27 SAS Institute Inc. SAS/STAT user's guide. Version 6, 4th edition, Cary, NC:SAS Institute Inc, 1989.

28 Wagenknecht LE, Perkins LL, Cutter GR,et al. Cigarette smoking behavior is strongly related to educational status: The CARDIA Study. Prev Med 1990;19:158-69

\section{Appendix 1}

Sites and key personnel of contributing MONICA centres.

I MONICA COLLABORATING CENTRES

Australia

University of Western Australia, Nedlands
Principal Investigator-M.S.T. Hobbs

Key personnel-K Jamrozik, P L Thompson, BK

Armstrong

University of Newcastle, Newcastle

Principal Investigator-A Dobson

Key personnel- $\mathrm{H}$ Alexander, $\mathrm{R}$ Heller

Belgium

Ghent State University, Ghent

Principal Investigator- $G$ de Backer

Key personnel-I De Craene, P Van Onsem, L

Van Parys

Interuniversity Association for the Prevention of

Cardiovascular Diseases, Brussels

Principal Investigator-M Jeanjean

Key personnel- $\mathrm{C}$ Brohet, $\mathrm{H}$ Kulbertus, $\mathrm{S}$ Degre

China

Beijing Heart, Lung and Blood Vessel Research Institute, Beijing

Principal Investigator-Wu Zhaosu

Former Principal Investigator-Wu Ying-Kai

Key personnel for risk factor surveys-Yao

Chonghua, Zhang Ruisong

Czech Republic

Institute for Clinical and Experimental Medicine, Prague

Principal Investigator-Z Skodová

Key personnel-Z Pisa, L Berka, Z Cicha, R Emrová, J Pikhartová, P Vojtisek, J Vorlicek, E Wiesner

Denmark

Copenhagen University Hospital, Glostrup

Principal Investigator- $M$ Schroll

Key personnel-M Kirchhoff, A Sjøl, T Joergensen

Finland

National Public Health Institute, Helsinki

Principal Investigator-J Tuomilehto

Former Principal Investigator-P Puska

Key personnel for risk factor surveys-C-G Gref,

$\mathrm{H}$ Korhonen, $\mathrm{M}$ Jauhiainen

France

Country Coordinator-J Richard

National Institute of Health and Medical Research (U258), Paris

Key personnel-A Bingham

National Institute of Health and Medical Research (INSERM 326), Toulouse

Principal Investigators-JP Cambou, J Ferrieres Key personnel-J-B Ruidavets

Institute of Hygiene-Faculty of Medicine, Strasbourg

Principal Investigators-D Arveiler, P Schaffer

Key personnel-I Escudero, V Baas

Pasteur Institute and Study and Research Group on Myocardial Infarction, Lille

Principal Investigators-P Amouyel, $M$ Montaye-Faivre

Former Principal Investigators-J-L Salomez, M-C Nuttens

Key personnel-N Marecaux, C Steclebout

Germany

GSF-Institute of Epidemiology, Neuherberg/ Munich

Principal Investigator-U Keil

Key personnel-J Stieber, A Döring, B Filipiak, U Härtel, HW Hense

Centre for Epidemiology \& Health Research, Berlin (from October 1990 Previously German Democratic Republic)

Principal Investigators-W Barth, L Heinemann Key personnel-A Assmann, S Böthig, G Voigt, $S$ Brasche, D Quietsch, E Classen 
Bremer Institute for Prevention Research and

Social Medicine, Bremen

Principal Investigator-E Greiser

Co-Principal Investigator-B Herman

Key personnel - G Studemann

Department of Clinical and Social Medicine of the University

Medical Clinic, Heidelberg

Principal Investigator-E Nussel

Former Co-Principal Investigator-E OstorLamm

Key personnel-R Scheidt, W Morgenstern, M Stadler

Iceland

Heart Preventive Clinic, Reykjavik

Principal Investigator-N Sigfússon

Key personnel-II Gudmundsdóttir, I Stefánsdóttir, Th Thorsteinsson, $\mathrm{H}$ Sigvaldason Italy

Institute of Cardiology, Regional Hospital, Udine

Principal Investigator-GA Feruglio

Key personnel-D Vanuzzo, L Pilotto, G Cignacco, M Scarpa, M Palmieri, M Spanghero, $R$ Marini, G Zilio

University of Milan, Institute of Occupational Health, Milan

Principal Investigators-GC Cesana, M Ferrario Key personnel-R Sega, P Mocarelli, G DeVito Lthuania

Kaunas Medical Academy Institute of Cardiology, Kaunas

Principal Investigator-J Bluzhas

Key personnel for risk factor survey-S Domarkiene, A Tamosiunas, $\mathrm{R}$ Reklaitiene

New Zealand

University of Auckland, Auckland

Principal Investigator- $\mathbf{R}$ Beaglehole

Key personnel-R Jackson, R Bonita, A Stewart,

D Mahon, W Bingley

Poland

Unit of Clinical Epidemiology and Population

Studies, School of Public Health, Jagiellonian

University, Krakow

Principal Investigator-A Pajak

Former Principal Investigator-J Sznajd

Key personnel-E Kawalec, T Pazucha, M Malczewska, R Morawski, A Celinski, U Zeman

National Institute of Cardiology, Warsaw, Department of Cardiovascular Epidemiology and Prevention

Principal Investigator-SL Rywik

Key personnel-G Broda (coordinator), M Polakowska, P Kurjata, H Wagrowska

Romania

Medical Institute, Fundeni Hospital, Bucharest

Principal Investigators-C Carp, I Orha

Key personnel-E Apetrei, I Coman, M Tarlea

Russian Federation

State Research Centre for Preventive Medicine,

Moscow

Principal Investigator-TA Varlamova

Key personnel-A Britov, V Konstantinov, L

Pavlova, A Alexándri, O Konstantinova

Institute of Internal Medicine, Novosibirsk

Principal Investigator-YuP Nikitin

Key personnel-S Malyutina, I Shalaurova

Spain

Institute of Health Studies, Department of

Health and Social Security, Barcelona
Principal Investigators-S Sans, I Balaguer-Vintró

Key personnel-Ll Balanà, G Paluzie, T Puig

Sweden

Department of Medicine, Ostra Hospital, Göteborg

Principal Investigator-L Wilhelmsen

Key personnel - $S$ Johansson, S Piros, G Lappas, Umeả University Hospital, Luleà-Boden Hospital and Kalix Hospital, Departments of Medicine

Principal Investigator-K Asplund, F Huhtasaari Key personnel-B Stegmayr, V Lundberg Switzerland

University Institute of Social and Preventive Medicine, Lausanne

Principal Investigator-F Gutzwiller (Zürich)

Key personnel-M Rickenbach, V Wietlisbach, F Barazzoni, D Hausser

United Kingdom

The Queen's University of Belfast, Belfast, Northern Ireland

Principal Investigator-A Evans

Key personnel-E McCrum, T Falconer, S Cashman

University of Dundee, Dundee, Scotland

Principal Investigator-H Tunstall-Pedoe

Former Co-Principal Investigator (Population Surveys)-WCS Smith

Key personnel $-\mathrm{R}$ Tavendale, $\mathrm{K}$ Barrett, $\mathrm{C}$ Brown

Former key personnel-I Crombie, $M$ Kenicer USA

Stanford Center for Research in Disease Prevention, Stanford, California

Principal Investigator-SP Fortmann

Key personnel-A Varady, $M$ Hull, JW Farquhar Yugoslavia

Health Centre "Novi Sad", Novi Sad

Principal Investigator-M Planojevic

Former Principal Investigator-D Jakovljevic

Key personnel-A Svircevic, M Mirilov, T Strasser II MONICA MANAGEMENT CENTRE-GENEVA

World Health Organization, Geneva

Responsible Officer-I Gyarfas

Former Responsible Officers-Z Pisa, SRA Dodu, S Böthig

Key personnel-I Martin, MJ Watson, M Hill

III MONICA DATA CENTRE-HELSINKI

National Public Health Institute, Helsinki, Finland

Responsible Officer-K Kuulasmaa

Former Responsible Officer-J Tuomilehto

Key personnel-A-M Koivisto, A Molarius, V

Moltchanov, E Ruokokoski

IV MONICA STEERING COMMITTEE

A Evans (Chair), $M$ Hobbs (Chair Publications SubCommittee), $M$ Ferrario, $H$ Tunstall-Pedoe (Rapporteur), I Gyarfas, K Kuulasmaa, A Shatchkute (WHO, Copenhagen),

Consultants-A Dobson, Z Pisa, and OD Williams

IV PREVIOUS STEERING COMMITTEE MEMBERS

S Sans, F Gutzwiller, SP Fortmann, A Menotti, P Puska, SL Rywik, U Keil, R Beaglehole, former chiefs of CVD/HQ, Geneva, V Zaitsev, J Tuomilehto

Former Consultants-MJ Karvonen, RJ Prineas, M Feinleib, FH Epstein 